\title{
XXIII. On the spectrum of Liquid oxygen, and on the refractive indices of liquid oxygen, nitrous oxide, and ethylene
}

\section{Professor Liveing \& Professor Dewar}

To cite this article: Professor Liveing \& Professor Dewar (1892) XXIII. On the spectrum of Liquid oxygen, and on the refractive indices of liquid oxygen, nitrous oxide, and ethylene, Philosophical Magazine Series 5, 34:207, 205-209, DOI: 10.1080/14786449208620308

To link to this article: http://dx.doi.org/10.1080/14786449208620308

曲 Published online: 07 May 2010.

Submit your article to this journal $\pi$

Џll Article views: 4

Q View related articles $₫$

47 Citing articles: 4 View citing articles 지 


\section{$\left[\begin{array}{ll}205 & ]\end{array}\right.$}

XXIII. On the Spectrum of Liquid Oxygen, and on the Refractive Indices of Liquid Oxygen, Nitrons Oxide, and Ethylene. $B y$ Professors Liveing and Dewar*.

TN September 1888 were described in this Magazine (p. 286)

1 the absorption-spectrum of oxygen gas in various states of compression. At lower pressures the absorptions known in the solar spectrum as A and B were most conspicuous, and as the pressure increased the other bands described by Jannsen came out with increasing intensity. The former appear to be due to the molecules of oxygen, and increase in intensity directly with the mass of the oxygen producing them ; while the latter appear to arise from the mutual action of the molecules on one another, since their intensity is dependent on the density as well as the mass of the oxygen producing them.

With the small dispersion employed in these observations the absorptions $A$ and $B$ were not resolved into lines as in the solar spectrum, but they liad otherwise the sarne general characters: A consisted of two bands, and both $A$ and $B$ were sharply defined on the more refrangible edge and gradually faded out on the less refrangible side. Considering how much more diffuse the lines forming these groups in the solar spectrum become as the sun gets nearer the horizon (see $\mathrm{M}^{\mathrm{c}}$ Clean's photographs), it is probable that, under the circumstances of our experiments, they would not have been rasolvable into lines even with higher dispersion.

Subsequently, in a paper read at the Royal Society (Proc. Roy. Soc. vol. xlvi. p. 222), we described our observations on the absorption of a thickness of 12 millim. of liquid oxygen. We noticed, as Olszewski had done, the strongest three of the diffuse bands seen in the spectrum of the compressed gas, but could not detect $A$. The mass of oxygen in 12 millim. of the liquid was not enough to make A visible.

We have since made observations with larger quantities of liquid oxygen. For this purpose we have used a glass tube of the form shown at $a$ in the annexed figure, about $\frac{3}{4}$ inch in diameter and 3 inches in length. This tube had the ends blown as flat and clear as possible, and it was enclosed in a box with glass sides $b c d$, and the air in the box well dried, in order to prevent the deposition of hoar-frost on the tube. The liquid oxygen was poured into the tube at the pressure of the atmosphere, and at first, of course, boiled violently, until the tube was reduced to the temperature of boiling oxygen, $-181^{\circ}$,

* Communicated by the Authors. 
after which the liquid boiled slowly and quietly. Through the length of the tube (that is, a thickness of about 3 inches

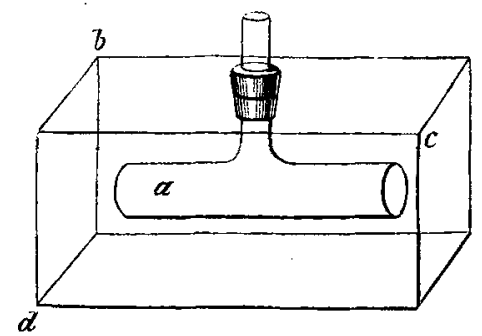

of liquid oxygen) we viewed the hot pole of an electric are with a spectroscope having two calcite prisms of $30^{\circ}$ and one of $60^{\circ}$. As reference-rays we used the red potassium-lines, of which the positions with reference to $A$ and $B$ were well determined by Kirchhoff, and confirmed by our own observations. These lines were easily obtained by dropping a little of a potassium salt into the are.

The diffuse bands previously seen both in the gas and liquid were all of exceptional strength, but we did not notice any addition to their number except a faint band just above $G$. In place of $A$ we observed a band, but different from $A$ in the following remarkable particulars. Instead of having a sharp edge on the more refrangible side and fading gradually towards the less refrangible side, its position appeared to be reversed; the sharp edge was on the less refrangible side, and it faded away gradually on the more refrangible side. Moreover its sharp, less refrangible edge did not coincide with the sharp edge of $A$, but reached very nearly to the more refrangible of the two potassium-lines, that is, had a wave-length of nearly 7660. At the same time the band extended beyond the sharp edge of $\mathrm{A}$ on the more refrangible side. There was no indication that it was resolvable into lines, or even into two bands. Turning to the place of $B$ in the spectrum we were not able, with that thickness of oxygen, to detect any band in that place. Olszewski (Wied. Ann. xlii. p. 663), with a thickness of 30 millim. of liquid oxygen, observed a somewhat faint band corresponding to $A$, which with a Rutherford prism was not resolvable into lines, but he has not noticed the reversed position of the band.

Using a similar tube for the liquid oxygen, but six inches long, the band at A came out very much stronger and extended much further on the more refrangible diffuse side, but was not conspicuously expanded on the other side, and did not hide the potassium-line. At the same time a fainter band 
appeared at the place of $\mathrm{B}$. This had precisely the same character as that at $\mathrm{A}$; that is, it had its sharp edge on the less refrangible side and faded gradually on the more refrangible side. Its sharp edge also did not coincide with the sharp edge of $\mathrm{B}$, but reached nearly to the red potassium-line $\lambda 6913$. By estimation, using the potassium-lines for comparison, we put the wave-length of the less refrangible edge at about $\lambda 6905$, while its diffuse side was visible to about $\lambda 6870$, that is, barely to the place of the strong edge of $\mathrm{B}$.

It is plain that these two bands are related to each other in the same way as the solar groups A and B are related, and we cannot avoid the conclusion that they represent $A$ and $B$, but modified by the change of the absorbent from the gaseons to the liquid state.

If, as there is good reason to think, $A$ and $B$ are the absorptions of free molecules of oxygen, the persistence of these absorptions in the liquid seems to show that the molecules in the liquid are the same as in the gas. At the same time the changes they undergo ought to throw some light on the nature of the change in passing from the gaseous to the liquid state, as well as on the causes which produce the sequences of rays which are called channelled spectra.

We have noticed, as Olszewski also has noticed, that liquid oxygen is distinctly blue. This is, of course, directly connected with its strong absorptions in the orange and yellow. On looking at a mass of liquid oxygen through a direct-vision spectroscope in any direction the scattered light shows the strong bands plainly. Indeed they remain visible when the oxygen has evaporated to the last drop, and they increase in intensity as the liquid is cooled, so that when the pressure on the liquid is reduced and the oxygen cooled by its own evaporation to $-200^{\circ}$ they become exceedingly black. Olszewski states that this blue colour is not, so far as he could make out, due to ozone, and we are of the same opinion. Ozone dissolves easily in liquid oxygen and imparts to it an indigo-blue colour. Such a solution when poured into a saucer of rock-salt assumes the spheroidal state, and as the oxygen evaporates becomes more concentrated, and finally explodes with considerable violence. In the dilute solution we could not detect any absorptions due to the ozone. We attempted to obtain a larger quantity of liquid ozone, or of a concentrated solution, for the observation of its spectrum. Oxygen oxonized in a tube cooled by solid carbonic acid gave small beautiful cobalt-blue drops of liquid, but when a few of these drops collected together in a tube immersed in liquid oxygen to cool it to $-181^{\circ}$, they exploded and blew the whole 
apparatus to pieces, comminuting the tube to fine powder. This instability of ozone, equally at very low and at high temperatures, is a significant fact in regard to the form of chemical energy. It seems probable that it is connected with the great absorbent power of ozone. The radiant energy absorbed must give rise to molecular movements which may, we conceive, set up disintegration.

The determination of the refractive index of liquid oxygen, at its boiling-point of $-182^{\circ} \mathrm{C}$., presented more difficulty than would have been anticipated. The necessity for enclosing the vessel containing the liquid in an outer case to prevent the deposit of a layer of hoar-frost which would scatter all the rays falling on it, rendered manipulation difficult; and hollow prisms with cemented sides cracked with the extreme cold. It was only after repeated attempts, involving the expenditure of a whole litre of liquid oxygen on each experiment, that we succeeded in getting an approximate measure of the refractive index for the $\mathrm{D}$ line of sodium. The mean of several observations gave the minimum deviation with a prism of $59^{\circ} 15^{\prime}$ to be $15^{\circ} 11^{\prime} 30^{\prime \prime}$, and thence $\mu=1 \cdot 2236$. The density of liquid oxygen at its boiling-point of $-182^{\circ} \mathrm{C}$. is $1 \cdot 124$, and this gives for the refraction-constant, $\frac{\mu-1}{d}=1 \cdot 989$, and for the refraction-equivalent $3 \cdot 182$. This corresponds closely with the refraction-equivalent deduced by Landolt from the refractive indices of a number of organic compounds. Also it differs little from the refraction-equivalent for gaseous oxygen, which is $3 \cdot 0316$. This is quite consistent with the supposition that the molecules of oxygen in the liquid state are the same as in the gaseous.

If we take the formula $\frac{\mu^{2}-1}{\left(\mu^{2}+2\right) d}$ for the refraction-constant we find the value of it for liquid oxygen to be $\cdot 1265$, and the corresponding refraction-equivalent $2 \cdot 024$. These are exactly the means of the values found by Mascart and Lorenz for gaseous oxygen. The inherent difficulties of manipulation, and the fact that the sides of the hollow prism invariably became coated with a solid deposit, perhaps solid nitrogen, which obscured the image of the source of light, have hitherto prevented our determining the refractive indices for rays other than $\mathrm{D}^{*}$.

* This will be prosecuted further, however. The refractive index of oxygen has an important bearing on the electro-magnetic theory of light, considering that we are dealing with a magnetic liquid. The poiarizing 
The determination of the refractive indices for liquid nitrous oxide did not present so great difficulties. The minimum deviations for the rays $C, D, F, G$, and for the lithium ray $\lambda 6705.5$, and the indium ray $\lambda 4509 \cdot 6$, were found to be, respectively, $22^{\circ} 53^{\prime}, 23^{\circ}, 23^{\circ} 18^{\prime}, 23^{\circ} 33^{\prime}, 22^{\circ} 52^{\prime}$. and $23^{\circ} 28^{\prime}$. The corresponding values for $\mu$ are 1.329 , $1.3305,1.3315,1.3378,1.3257$, and 1.3368 .

The specific gravity of liquid nitrous oxide at its boilingpoint of $-90^{\circ}$ ( . was found, by weighing 100 cubic centim. of the liquid, to be 1-255.

This gives, for the $\mathrm{D}$ ray, $\frac{\mu-1}{d}=0.2634$ and for the molecular refraction 11.587 . Or, if we take the other formula, $\frac{\mu^{2}-1}{\left(\mu^{2}+2\right) d}=\cdot 163$ and the corresponding molecular refraction $7 \cdot 163$. Subtracting the refraction-equivalent for oxygen we get for the molecular refraction of nitrogen 8.405 or $5 \cdot 139$ according to the formula used. Mascart's determination of the index of refraction of gaseous nitrous oxide for the $D$ ray was 1.000516 and the corresponding molecular refraction 11.531 , or $7 \cdot 69$, according to the formula used, and in this case the older formula for the refraction-equivalent satisfies the condition of continuity between the gaseous and liquid states better than the newer.

It was more difficult to obtain the refractive indices for liquid ethylene on account of its irregular boiling. Liquid oxygen and nitrous oxide boil steadily, but ethylene in sudden bursts of large volumes of vaponr. The minimum deviation for the $\mathrm{D}$ ray was found to be $25^{\circ} 29^{\prime}$, approximately. This gives $\mu=1.3632$, and, since the density of the liquid at its boiling-point of $-100^{\circ} \mathrm{C}$. is $0.58, \frac{\mu-1}{d}=0.627$ and $\frac{I^{\prime} \mu^{2}-1}{\left(\mu^{2}+2\right) d}$ $=0.384$. The corresponding numbers for gaseous ethylene, according to Mascart, are 0.578 and 0.385 . The agreement for the second formula is close, but we doubt if much stress can be laid on this, inasmuch as we know that the liquid ethylene contained a small quantity of ether.

angle corresponding to the index of refraction found above for liquid oxygen is $50^{\circ} 45^{\prime}$, and one of us has found that when liquid oxygen is cooled to $-200^{\circ}$ by its own evaporation at reduced pressure so as to present a steady surface, and the image of a candle is viewed by reflexion at that surface, the light is very completely polarized when the incidence is at that angle.

Phil. Mag. S. 5. Vol, 34. No. 207. Aug. 1892. 